\title{
PERAN FILANTROPI ZAKAT DALAM PENGENTASAN KEMISKINAN DI INDONESIA
}

\author{
Feri Irawan \\ Sekolah Tinggi Agama Islam Nahdlatul Wathan \\ Samawa Sumbawa Besar NTB \\ Email: irawanferi23@gmail.com
}

\begin{abstract}
Poverty is a serious problem that must be borne by the Indonesian state, poverty is mostly done by the government but the poverty rate is still very high, in an effort to alleviate poverty a synergy of philanthropic synergy is needed. This research describes how the contribution of alms philanthropy in poverty alleviation efforts in Indonesia. This research was conducted with qualitative approval, and data collection using non-participatory collection techniques and documentation. This research shows that philanthropic charity towards poor families which is a charity is also empowerment, as well as sources of supply of production that supports the improvement of human welfare in Indonesia.
\end{abstract}

Keywords: Philanthropy, Alms, Poverty

\section{Pendahuluan}

Kemiskinan merupakan tema yang menarik diperbincangkan terutama bagi kalangan ilmuwan saat ini. Banyak kajian menawarkan solusi guna menanggulangi kemiskinan, akan tetapi wajah kemiskinan tetap eksis di tengah dinamika perubahan zaman. Upaya untuk menanggulangi masalah kemiskinan dilakukan terus menerus oleh para 
pakar di sepanjang zaman dalam upaya menemukan bentuk yang ideal pengentasan kemiskinan. Tema kemiskinan dikaji tidak hanya oleh negara-negara berkembang tetapi juga negara-negara maju. Sebelum mengenal kajian-kajian ilmiah mengenai masalah kemiskinan, masyarakat sudah menjalankan tradisi yang merespon terhadap permasalahan kemiskinan dalam bentuk pemberian. Kegiatan "memberi" dalam berbagai bentuknya tidak terbatas dalam bentuk uang atau barang melainkan juga pekerjaan atau berbagai upaya untuk meringankan beban orang miskin serta meningkatkan kesejahteraannya disebut sebagai filantropi. ${ }^{1}$

Menurut James O. Midgley, filantropi merupakan salah satu pendekatan dari tiga pendekatan untuk mempromosikan kesejahteraan termasuk di dalamnya upaya pengentasan kemiskinan yaitu pendekatan social service (social administration), social work dan philanthropy. Filantropi sebagai salah satu modal sosial telah menyatu di dalam kultur komunal (tradisi) yang telah mengakar sejak lama khususnya di masyarakat pedesaan. Fakta kultural menunjukkan bahwa tradisi filantropi dilestarikan melalui pemberian derma kepada teman, keluarga, dan tetangga yang kurang beruntung. Ciri lainnya ditunjukkan dengan tuntutan masyarakat untuk memprioritaskan tujuan meringankan beban orang miskin yang jumlahnya naik 1 hingga 48\% selama krisis ekonomi yang melanda Indonesia sejak tahun 1997 . $^{2}$

Disamping itu, filantropi juga merupakan salah satu unsur dalam ajaran agama yang memperhatikan masalah duniawi terutama masalah kemiskinan. Secara fungsional, agama memegang peranan penting dalam kehidupan masyarakat, baik bagi masyarakat tradisional maupun modern, agama merupakan tempat mereka mencari makna hidup yang final dan ultimate sehingga segala bentuk perilaku dan tindakan selalu berkiblat pada tuntunan agama (way of life). ${ }^{3}$ Agama tidak hanya menuntun umatnya untuk mengurusi kehidupan ukhrowi (akhirat) saja akan tetapi juga menyangkut kehidupan duniawi terutama masalah-masalah sosial seperti kemiskinan.

Penelitian ini bertujuan untuk melihat peran filantropi zakat dalam upaya pengentasan kemiskinan di Indonesia. Hal ini didasarkan pada asumsi bahwa masyarakat di Indonesia yang mayoritas penduduknya merupakan pemeluk agama Islam tidak hanya memiliki tradisi filantropi

\footnotetext{
${ }^{1}$ Zaim Saidi, dkk, Kedermawanan Untuk Keadilan Sosial, (Jakarta: Piramedia, 2006), hal. 4-5

2 Pirac, Investing in Our Selves; Giving and Fund Raising In Indonesia, (Phillipine: Asian

2 Pirac, Investing in Our Selves; Giving and Fund Raising In Indonesia, (Phillipine: Asian Development Bank, 2002), hal. 9

${ }^{3}$ Soelaeman, Ilmu Sosial Dasar, (Jakarta: PT.Eresco, 1995), hal. 63
} 
agama, akan tetapi juga memiliki tradisi filantropi sosial. Fenomena sosial 'tolong-menolong'dalam kerangka saling membantu antara satu dengan yang lain merupakan ciri utama dari kedermawanan. Kedermawanan para pemilik lahan di pedesaan untuk sharing pendapatan baik melalui aktivitas 'memberi' dalam berbagai bentuknya terhadap keluarga miskin adalah potensi dan tradisi pengentasan kemiskinan sudah berkembang di dalam masyarakat pedesaan. ${ }^{4}$ Praktik filantropi seperti ini berlangsung cukup lama di dalam masyarakat, meski pola prakteknya bersifat interpersonal dan tidak terorganisir. Disamping itu, kesadaran berfilantropi masyarakat di pedesaan tidak hanya bersumber dari normanorma sosial yang menjunjung tinggi nilai solidaritas gotong-royong dan saling membantu, akan tetapi juga bersumber dari nilai-nilai religiusitas sangat dimungkinkan keberadaannya karena ajaran-ajaran agama mengajarkan dan menganjurkan untuk berbuat kebajikan. ${ }^{5}$

\section{Konsep Filantropi}

Definisi filantropi berasal dari Philanthhopy: Philos (cinta) dan anthropos (manusia). Lebih jauh lagi konseptualisasi filantropi adalah praktik giving, services, dan association secara sukarela untuk membantu pihak lain. Bahkan bisa dimaknai Voluntary action for the public good atau tindakan sukarela untuk kepentingan publik. Filantropi sendiri hadir dari semangat untuk mendayaguna-kan dan menumbuhkan kemandirian civil society. Filantropi dalam sejarah kelahirannya sampai dengan sekarang berkembang dalam 2 (dua) varian besar yakni filantropi tradisional dan filantropi keadilan social. ${ }^{6} \mathrm{Hal}$ ini pula di tegaskan oleh Allien Shaw bahwa filantropi bukanlah sekedar karitas, akan tetapi lebih pada pendampingan yang bersifat pemberdayaan berdampak jangka panjang. ${ }^{7}$

Filantropi tradisional beraktifitas dalam ruang karitas, tidak berkelanjutan dan cenderung memaknai filantropi secara an sich. Sedangkan filantropi keadilan sosial menggali secara filosofis bahwa sebenarnya kelahiran nilai-nilai filantropi ini adalah menjawab permasalahan publik yang ada ditengah-tengah masyarakat dengan ciri

\footnotetext{
${ }^{4}$ Sairin, Perubahan Sosial Masyarakat Indonesia; Perspektif Antropologi, (Jogjakarta: Pustaka Pelajar, 2002), hal. 277

${ }^{5}$ Dwight F Burlingame, "Philanthropy" dalam Microsoft Encarta Standard 2006; Thomas M. Smith, 2004, "Religious Affiliation and Philanthropy", http://www.religionomics.com/erel/S2-Archives/REC04/Smith\%20-

\%20Religion \%20and\% 20philanthropy.pdf, diakses pada tgl 5-10-2007

${ }^{6}$ Prihatna, Filantropi dan keadilan sosial. Revitaliasasi Filantropi Islam. Jakarta: PBB UIN Syarif Hidayatullah dan The Ford Foundation. (2005), hal. 20

${ }^{7}$ Latief, Melayani umat: Filantropi Islam dan ideologi kesejabteraan kaum modernis. Jakarta. PT Gramedia Pustaka Utama: (2010), hal. 10
} 
khas program yang berkelanjutan, bergerak di ranah makro, menyelesaikan problem di tingkat struktur dan mengubah sistem.

Universalitas konsep filantropi tidak dapat dipungkiri berdampak pada praktik-praktik filantropi yang ada di masyarakat. Begitupun dengan pemahaman filantropi dalam perspektif agama yang kemudian menambah dimensi baru implementasi filantropi keagamaan. Selanjutnya konsep filantropi tidak hanya semata-mata bersinggungan dengan material saja, W.K. Kellog Foundation mendefinisikan secara luas konsepsi filantropi yakni memberikan waktu, uang, dan pengetahuan bagaimana cara mengembangkan kebaikan bersama. ${ }^{8}$ Artinya keterlibatan secara luas seluruh aktifitas manusia dalam berbagai bidang dengan penuh kerelaan, partisipasi, dedikasi, gagasan, waktu luang, kontribusi materi merupakan bagian yang tidak dapt dipisahkan dari konsepi filantropi.

Gagasan Helmut K. Anheier dan Diana Laet tentang 'creative philanthropy' patut diapresiasi sebagai analisis pendekatan-pendekatan filantropi yang cukup tepat dalam kondisi masyarakat modern'. Pertama, pendekatan karitas (charity approach), pendekatan ini cenderung menyoroti gejala-gejala dari problem social daripada akar permasalahannya sehingga dampaknya tidak begitu terasa bahkan hanya temporer. Kedua, pendekatan 'filantropi ilmiah' (scientific philanthropy) yang betujuan untuk menyelesaikan masalah-masalah sosial dari penyebabnya. Akan tetapi, pendekatan ini sering gagal karena terfokus dalam analisis pendidikan dan riset semata, sehingga kemampuan untuk melihat seberapa lama, seberapa besar biaya, seberapa kompleks sering diabaikan, artinya dalam sisi praktis sering diabaikan. Ketiga, pendekatan 'new scientific philanthropy' atau neo filantropi ilmiah, pendekatan ini lebih menekankan pada proses bukan peran, dan kurang memperhatikan nilai-nilai unik lembaga filantropi yang ada dan membedakan dengan lembaga lain.

Pembahasan tentang filantropi Islam seharusnya tidak terlepas dari perkembangan konsepsi filantropi pada umumnya. Namun lebih khusus makna filantropi Islam sendiri didasari pada hal-hal di bawah ini. ${ }^{10}$

1. Tidak ada satu dikotomi antara usaha-usaha spiritual dengan material dalam kehidupan manusia.

2. Menjadi karakter, tujuan, dan fungsi komunitas muslim (relevan makhluk sosial).

3. Konsep trusteeship mengenai kekayaan dan property.

${ }^{8}$ Ibid,,, hal. 24

${ }^{9}$ Ibid,, hal. 26

${ }^{10}$ Prihatna, Filantropi dan keadilan sosial... Hal. 23 


\section{Fungsi Ekonomi Zakat dalam Islam}

Zakat adalah suatu sistem baru yang unik dalam sejarah kemanusiaan. Suatu sistem yang belum pernah ada pada agama-agama samawi juga dalam peraturan-peraturan manusia. Zakat mencakup sistem keuangan, ekonomi, sosial, politik, moral dan agama sekaligus. ${ }^{11}$ Zakat adalah sistem keuangan dan ekonomi karena ia merupakan pajak harta yang ditentukan. Sebagai sistem sosial karena berusaha menyelamatkan masyarakat dari berbagai kelemahan. Sebagai sistem politik karena pada asalnya negaralah yang mengelola pemungutan dan pembagiannya. Sebagai sistem moral karena ia bertujuan membersihkan jiwa dari kekikiran orang kaya sekaligus jiwa hasud dan dengki orang yang tidak punya dan yang lebih utama sebagai sistem keagamaan karena menunaikannya adalah salah satu tonggak keimanan dan ibadah tertinggi dalam mendekatkan diri kepada Allah.

Zakat itu sendiri menjadi bukti bahwa ajaran Islam itu dari Allah SWT. Zakat merupakan salah satu ciri dari sistem ekonomi Islam, karena zakat merupakan salah satu implementasi azas keadilan dalam sistem ekonomi Islam. Sebagaimana yang diungkapkan oleh Monzer Kahf bahwa tujuan utama dari zakat adalah untuk mencapai keadilan social ekonomi. Zakat merupakan transfer sederhana dari bagian dengan ukuran tertentu harta si kaya untuk dialokasikan kepada si miskin. ${ }^{12}$

Lebih jauh Ali dan Zaman menerangkan bahwa tujuan zakat adalah: (1) mengangkat derajat fakir miskin; (2) membantu memecahkan masalah para gharimin, ibnu sabil dan mustahik lainnya; (3) membentangkan dan membina tali persaudaraan sesama umat Islam dan manusia pada umumnya; (4) menghilangkan sifat kikir dan loba para pemilik harta; (5) menghilangkan sifat dengki dan iri (kecemburuan sosial) dari hati orang-orang miskin; (6) menjembatani jurang antara si kaya dengan si miskin di dalam masyarakat; (7) mengembangkan rasa tanggung jawab sosial pada diri seseorang terutama yang memiliki harta; (8) mendidik manusia untuk berdisiplin menunaikan kewajiban dan menyerahkan hak orang lain padanya; (9) sarana pemerataan pendapatan untuk mencapai keadilan sosial. ${ }^{13}$

\footnotetext{
11 M. Abdul Mannan, Teori dan Praktek Ekonomi Islam, (Yogyakarta: PT. Dana Bhakti Prima Yasa, 1997), hal. 256.

12 Monzer Kahf, Potential Effects Of Zakah On Government Budget, dalam IIUM Journal of Economics \& Management 5, No. 1. Tahun 1997

13 Mohammad Daud Ali, Sistem Ekonomi Islam Zakat dan Wakaf, (Jakarta : UI Press, 1988), h. 21 dan Hasanuz Zaman, S. M., Islamic Criteria For The Distribution Of Tax Burden (The Mix of Direct and Indirect Taxes and The Offsetting Fuction of Zakat), dalam Journal of Islamic Economics, Vol. 3, No. 1. Januari Tahun 1993.
} 
Sedangkan menurut Mannan secara umum fungsi zakat meliputi bidang moral, sosial dan ekonomi. Dalam bidang moral, zakat mengikis ketamakan dan keserakahan hati si kaya. Dalam bidang sosial, zakat berfungsi untuk menghapuskan kemiskinan dari masyarakat. Di bidang ekonomi, zakat mencegah penumpukan kekayaan di tangan sebagian kecil manusia dan merupakan sumbangan wajib kaum muslimin untuk perbendaharaan negara, karena tujuan zakat adalah transfer kekayaan dari masyarakat yang kaya kepada masyarakat yang kurang mampu, sehingga setiap kegiatan yang merupakan sumber kekayaan harus menjadi sumber zakat. $^{14}$

Selain fungsi di atas, zakat ternyata memberikan dampak secara makroeconomic, yaitu bahwa zakat memberikan pengaruh terhadap perilaku konsumsi, perilaku belanja pemerintah maupun perilaku investasi. ${ }^{15}$ Hal ini juga dinyatakan Karim bahwa zakat mempunyai pengaruh positif bagi pertumbuhan ekonomi. ${ }^{16}$ Senada dengan hal ini, menurut Kahf secara ekonomi bantuan zakat diberikan dalam bentuk konsumtif pada mustahik akan meningkatkan daya beli mustahik tersebut atas suatu barang yang menjadi kebutuhannya. Peningkatan daya beli atas suatu barang ini akan berimbas pada peningkatan produksi suatu perusahaan yang berarti akan terjadi penambahan kapasitas produksi, hal ini berarti perusahaan akan menyerap tenaga kerja lebih lebih banyak sehingga dapat menambah perekonomian negara secara agregat. ${ }^{17}$

\section{Reorientasi Zakat Dalam Mengentaskan Kemiskinan di Indonesia}

Melihat berbagai permasalahan zakat di atas, maka reorientasi zakat menjadi penting dilakukan agar potensi zakat dapat digali secara optimal dan berdampak bagi pengentasan kemiskinan. Reorientasi zakat ini dilakukan tidak hanya pada pemahaman dan konsep zakat namun juga manajemen zakat yang meliputi pengumpulan dan penyaluran dana zakat serta organisasi pengelola zakat. Hal ini senada dengan Miftah bahwa melihat potensi zakat dalam mengentaskan kemiskinan, maka pembaharuan zakat menjadi penting dilakukan. ${ }^{18}$

\footnotetext{
14 M. Abdul Mannan, Teori dan Praktek Ekonomi Islam, (Yogyakarta: PT. Dana Bhakti Prima Yasa, 1997), h. 256.

15 Akhmad Akbar Susamto, Zakah As Deductible For Taxable Income: A Macroeconomic Perspektive, dalam IQTISAD Journal of Islamic Economics, Vol. 4, No. 2 Tahun 2003

16 Karim, Adiwarman, Ekonomi Islam Suatu Kajian Ekonomi Makro, (Jakarta: The International Institute of Islamic Thought/IIIT Indonesia, 2002), h. 133.

${ }^{17}$ Monzer Kahf, Potential Effects Of Zakah On Government Budget, dalam IIUM Journal of Economics \& Management 5, No. 1. Tahun 1997.

18 A. A. Miftah, Pembaharuan Zakat Untuk Pengentasan Kemiskinan Di Indonesia, dalam Jurnal Innovatio, Vol. VII, No. 14, Juli-Desember 2008, h. 430
} 
Adapun upaya yang perlu dilakukan dalam rangka reorientasi zakat adalah:

1. Merubah cara pandang umat Islam terhadap zakat. Cara pandang yang lebih kental nuansa figh klasik harus ditambah dengan cara pandang lain yang memungkinkan zakat dapat diberdayakan. Jika selama ini sebagian besar umat Islam masih memandang zakat sebagai ibadah yang terlepas kaitannya dengan persoalan sosial dan ekonomi, maka saat ini zakat harus dipandang sebagai sumber kekuatan ekonomi umat yang dapat dipergunakan untuk menyelesaikan berbagai permasalahan sosial umat Islam Perubahan cara pandang zakat dimulai dari pembaharuan terhadap fiqh zakat itu sendiri. Zakat harus ditempatkan dalam aspek muamalat (ekonomi) atau menjadi kajian yang berdiri sendiri sebagaimana yang dilakukan oleh Yusuf Qardawi melalui kitabnya Fiqh Zakat. Dalam karya ini zakat tidak hanya dilihat dari sisi ajaran normatifnya saja, tetapi zakat juga dilihat dari sisi historis dan filosofisnya. ${ }^{19}$ Melalui pendekatan historis, filosofis dan normative akan terjadi perubahan pandangan terhadap zakat.

2. Perbaikan aspek manajemen pada lembaga zakat merupakan hal yang sangat penting dan fundamental. Salah satu penyebab ketidak percayaan masyarakat terhadap lembaga zakat adalah karena pengelolaan zakat yang tidak transparan dan tidak akuntabel, padahal kinerja penghimpunan dan pendayagunaan dana zakat lebih banyak ditentukan oleh legitimasi dan reputasi lembaga pengumpul, bukan oleh sentralisasi kelembagaan oleh pemerintah. Kinerja zakat justru meningkat setelah dikelola oleh masyarakat sipil. Maka, agenda terbesar dunia zakat nasional saat ini adalah mendorong tata kelola yang baik dengan mendirikan otoritas zakat yang kuat dan kredibel, yang akan memiliki kewenangan regulasi dan pengawasan di tiga aspek utama, yaitu kepatuhan syariah, transparansi dan akuntabilitas keuangan, serta efektivitas ekonomi dari pendayagunaan dana zakat.

3. Kompleksitas masalah zakat dan potensinya yang sangat besar dalam pembangunan ekonomi mengharuskan zakat sudah saatnya dikelola secara professional. Sistem rekruitmen pengelola zakat sudah saatnya mengarah pada sistem rekruitmen terbuka dan kompetitif dalam rangka menjaring pengelola-pengelola zakat yang profesional sesuai dengan bidang-bidang yang dibutuhkan dalam

${ }^{19}$ Yusuf Qardhawi, Hukum Zakat, (Jakarta : Litera Antar Nusa, 2007), h. 881. 
memajukan kelembagaan amil zakat. Peningkatan aspek profesionalitas pengelolaan zakat berdampak pula pada sistem penggajian pengelola zakat sesuai dengan standar kerja, karena hal ini akan ikut menentukan kinerja organisasi.

4. Inovasi dalam pola distribusi dana zakat karena selama ini ada kesan bahwa zakat melanggengkan kemiskinan. Hal ini setidaknya dapat dilihat dari penerima zakat yang tidak pernah berubah statusnya sebagai mustahik. Tidak seimbangnya sisi penerimaan zakat dan jumlah orang yang miskin di sisi sebaliknya membuat santunan tidak akan efektif dalam mengentaskan kemiskinan selain itu zakat yang tidak tepat sasaran juga menjadi penyebab gagalnya fungsi ekonomi zakat. Dalam mengatasi masalah ini perlu mencontoh apa yang telah dilakukan oleh Pusat Zakat Umat (PKU) Persis Garut. Lembaga zakat ini telah melakukan proses pemilihan orang yang berhak menerima dana ZIS (mustahik) yang dilakukan melalui beberapa tahap prosedural, sehingga diharapkan para mustahik-nya bisa tepat sasaran.

Selain itu pola distribusinya pun diubah ke arah produktif tanpa meninggalkan sisi konsumtif. Zakat didayagunakan untuk mengatasi problem kemandirian di kalangan masyarakat miskin. Problem non-bankable yang melilit sebagian mustahik yang penghidupannya ada di sektor usaha informal menjadikan mereka tak berdaya untuk meningkatkan kapasitas usahanya, sehingga dibutuhkan akses permodalan yang lebih luas dan pendampingan. ${ }^{20}$ Beberapa LAZ telah melakukan pemberian modal terhadap mustahik dan kemudian melakukan pendampingan usaha agar usaha yang dilakukan berhasil sebagaimana yang dilakukan oleh LAZ Dana Peduli Umat Kaltim yang sejak tahun 2009 telah menyalurkan zakat produktif dengan program PKM (Pusat Kemandirian Masyarakat) yang bertujuan untuk membantu tercipta peningkatan dan pengembangan sumber daya dan ekonomi mustahiq. Besarnya dana zakat produktif adalah $10 \%$ dari dana zakat yang disalurkan. ${ }^{21}$

Program inovatif lainnya adalah penyediaan layanan publik yang seharusnya menjadi tanggung jawab pemerintah. Telah ada

\footnotetext{
${ }^{20}$ Sri Hartoyo, Mengenal Pusat Zakat Umat Persis Garut dalam Iqtishodia, Jurnal Ekonomi Islam Republika 29 Juli 2010.

${ }_{21}$ Norvadewi \& Akhmad Nur Zaroni, 2009, Pendayagunaan Zakat Produktif di Lembaga Zakat dan Pengarubnya terhadap Peningkatan Usaha Ekonomi Umat (Studi Komparatif di BAZ Propinsi Kaltim dan LAZ DPU Kaltim), Hasil Penelitian, P3M Stain Samarinda, h. 40-41
} 
beberapa LAZ yang membuka program layanan kesehatan secara gratis, sekolah unggulan untuk dhuafa bebas biaya, dan program sejenis lainnya. Ini juga telah dilaksanakan oleh LAZ DPU Kaltim diantara programnya adalah beasiswa pendidikan berupa program anak asuh, cerah (celengan berkah), layanan kesehatan gratis, rumah Qur'an, dan lain-lain. ${ }^{22}$ Dari sekian program-program inovatif di atas memang dampaknya masih belum dirasakan secara makroekonomi, bahkan cenderung rentan terhadap perubahan kondisi akibat kebijakan-kebijakan pemerintah yang terkadang tidak mendukung. Dalam rangka mensinergikan BAZ dan LAZ, maka perlu memadukan peran negara dan masyarakat sipil dalam pengelolaan zakat.

Di Indonesia, peran tunggal pemerintah dalam pengelolaan zakat masih belum dapat dilakukan karena sistem birokrasi dan good governance masih lemah. Karena itu keterlibatan masyarakat sangat dibutuhkan. Namun menyerahkan pengelolaan zakat pada organisasi masyarakat sipil pun akan berdampak negative, karena setiap lembaga memiliki kecenderungan ideologis, budaya dan kepentingan yang berbeda. Sehingga peran pemerintah dan masyarakat sipil dalam pengelolaan zakat ibarat dua sisi mata uang. ${ }^{23}$ Sedangkan Didin Hafidhuddin (Ketua BAZNAS) menyatakan bahwa idealnya keberadaan BAZ dan LAZ harus tetap diakomodir karena keduanya memiliki kelemahan dan kelebihan. Keberadaan LAZ memunculkan kesadaran masyarakat membayar zakat semakin kuat sedangkan BAZ juga mempunyai kekuatan yang mengikat. Lebih lanjut Didin mengusulkan agar BAZ dan LAZ keduanya bisa dipadukan karena unsur negara penting, unsur masyarakat juga penting. ${ }^{24}$ Negara memberikan legitimasi politik dan penyedia sarana public sedangkan masyarakat sipil berperan sebagai pelaksana dan control terhadap pelaksanaan zakat di masyarakat. Alfitri menyatakan bahwa hubungan antara lembaga zakat yang dikelola sipil dan negara terletak pada peran dan pelaksanaan kewajiban. Secara hukum, zakat perlu dikelola oleh sebuah lembaga sehingga pelaksanaan zakat dapat dilakukan

\footnotetext{
22 Sumadi, (Direktur LAZ DPU Kaltim), 2011, dalam Nurani, Mitra Peduli Untuk Berbagi. Majalah Bulanan LAZ DPU Kaltim (Media Informasi Donatur).

${ }^{23}$ Asep Saefuddin Jahar, Zakat Antar Bangsa Muslim, Menimbang Posisi Realistis Pemerintah dan Organisasi Masyarakat Sipil dalam Zakat \& Empowering, Jurnal Pemikiran dan Gagasan, Vol. 1, No. 4, Agustus 2008, h. 16.

24 Anonim, Mengapresiasi Bangkitnya Civil Society Dalam Pengelolaan Zakat di Indonesia, dalam Zakat \& Empowering, Jurnal Pemikiran dan Gagasan, Vol. 1, No. 4 Agustus 2008, h. 41.
} 
dengan baik. Jika negara tidak terlibat untuk mengelola zakat karena negara berdasar sistem sekuler maka lembaga volunteer atau masyarakat sipil dapat melakukan perannya. ${ }^{25}$

5. UU Zakat No. 38 Thn. 1999. UU No. 38 tahun 1999 telah menjadikan tata kelola zakat yg kurang regulasi dan pengawasan. Dengan penyempurnaan UU Zakat ini akan mengukuhkan peran negara dalam memberi perlindungan bagi warga negara yang menjadi pembayar zakat (muzakki), mencegah penyalahgunaan dana zakat, memfasilitasi sektor amal untuk perubahan sosial. Qardhawi menyatakan bahwa Islam melibatkan negara dalam pengumpulan serta pembagian zakat melalui amil zakat. Hal ini jelas di dalam Al Qur'an dan hadits. ${ }^{26}$ Namun Faridi menyatakan bahwa peran negara yang dominan ini memiliki keunggulan dan kelemahan. Keunggulannya adalah negara mempunyai kekuatan enforcement dan mengontrol pembayaran zakat oleh masyarakat sehingga penghasilan zakat bisa ditargetkan sesuai dengan working plan. Kelemahannya adalah peran negara terlalu besar sehingga bisa menimbulkan penyimpangan karena lemahnya control dari masyarakat. ${ }^{27}$ Lebih jauh Qardhawi menambahkan agar zakat bisa optimal dalam pengumpulannya maka diperlukan tiga pengawasan. Pertama, keimanan seorang muslim dan kesadaran keagamaannya yang mendorongnya untuk melaksanakan kewajiban agama, kedua, hati nurani masyarakat yang terwujud dalam opini masyarakat (amar ma'ruf nahi munkar) dan ketiga, pengawasan dari pemerintah yang berwenang mengambil zakat, bahkan boleh memberikan sanksi kepada mereka yang tidak mau membayar zakat. ${ }^{28}$

Agar pengawasan ketiga ini bisa dilaksanakan maka UU Zakat baru ini harus berisikan desentralisasi pengelolaan zakat dengan regulator yang kuat dan kredibel, konsolidasi Organisasi Pengelola Zakat (OPZ) menuju dunia zakat nasional yang efisien, dan kemitraan pemerintah-OPZ untuk akselerasi pengentasan kemiskinan. Dengan konsolidasi dan sistem kelembagaan jejaring, pengelolaan zakat secara formal kelembagaan akan optimal. Semua potensi zakat dapat dihimpun, dan didayagunakan secara

\footnotetext{
25 Alfitri, The Law of Zakat Management and Non-Governmental Zakat Collectors in Indonesia, dalam The International Journal of Not-for-Profit Law, Vol. 8, January 2006.

${ }^{26}$ Yusuf Qardhawi, 1997, Norma dan Etika Ekonomi Islam, (Jakarta : Gema Insani Press, 1997), h. 253.

${ }^{27}$ Faridi, F. R, Theory of Fiscal Policy in An Islamic State, dalam J. Res. Islamic. Econ, Vol.1 No. 1 Tahun 1983.

${ }^{28}$ Yusuf Qardhawi, 1997, Norma dan Etika Ekonomi Islam, (Jakarta : Gema Insani Press, 1997), h. 253.
} 
profesional dan amanah untuk kesejahteraan umat. Di sisi lain, format kelembagaan khusus bagi UPZ akan memberdayakan potensi amil tradisional dengan tetap memberi peluang bagi penggunaan untuk kepentingan lokal.

Dari berbagai upaya yang telah dilakukan di atas, maka kinerja dunia zakat nasional harus ditingkatkan dengan mendorong kemitraan pemerintah dan OPZ untuk akselerasi pengentasan masyarakat dari kemiskinan. UU Zakat harus mengamanatkan bahwa pemerintah akan secara aktif mengikutsertakan OPZ dalam program penanggulangan kemiskinan. Kemitraan pemerintah-OPZ dalam program penanggulangan kemiskinan dapat berupa pemberian hibah maupun kontrak penyediaan jasa sosial dimana pemerintah yang akan menerapkan kriteria dan persyaratan bagi OPZ penerima dana program penanggulangan kemiskinan, seperti transparansi finansial, efektivitas pendayagunaan dana, dan kesesuaian dengan prioritas nasional/daerah.

\section{Penutup}

Zakat adalah suatu sistem baru yang unik dalam sejarah kemanusiaan. Sistem yang hanya ada di dalam Islam, dimana Zakat tidak hanya sebatas ibadah namun mencakup sistem keuangan, ekonomi, sosial, politik sekaligus moral. Sebagai sistem keagamaan karena menunaikannya adalah salah satu tonggak keimanan dan ibadah tertinggi dalam mendekatkan diri kepada Allah. Sebagai sistem sosial karena berusaha menyelamatkan masyarakat dari berbagai kelemahan. Sebagai sistem politik karena pada asalnya negaralah yang mengelola pemungutan dan pembagiannya dan sebagai sistem moral karena ia bertujuan membersihkan jiwa dari kekikiran orang kaya sekaligus jiwa hasud dan dengki orang yang tidak punya.

Zakat mempunyai fungsi ekonomi dalam mengentaskan kemiskinan bahkan zakat memberikan pengaruh signifikan terhadap makro ekonomi. Namun dalam kenyataannya fungsi ekonomi zakat ini belum bisa optimal dalam mengentaskan kemiskinan karena pengelolaan yang kurang professional. Di sini peran negara diperlukan dalam mengelola zakat. Peran ini bisa terwujud apabila ada reorientasi pemahaman zakat dan pengelolaan zakat agar zakat dapat diberdayakan secara optimal. Dalam hal ini perlu sinergi yang dinamis antara pemerintah dan masyarakat dalam optimalisasi peran zakat dalam mengentaskan kemiskinan di Indonesia. 


\section{DAFTAR RUJUKAN}

Alfitri, 2006, The Law of Zakat Management and Non-Governmental Zakat Collectors in Indonesia, dalam The International Journal of Not-forProfit Law, Vol. 8, January.

Ali, Mohammad Daud, 1988, Sistem Ekonomi Islam Zakat dan Wakaf, Jakarta, UI Press.

Anonim, Agustus 2008, Mengapresiasi Bangkitnya Civil Society Dalam Pengelolaan Zakat di Indonesia, dalam Zakat \&Empowering, Jurnal Pemikiran dan Gagasan, Vol. 1, No. 4.

Clark, Grace, 2001, Pakistan's Zakat System: A Policy Model for Developing Countries as A Means of Redistributing Income to The Elderly Poor, The Haworth Press.

Daud, Ma'mur (Penterjemah), 1993, Terjemah Hadits Shabih Muslim Jilid IVI, Jakarta: Widjaya.

Faridi, F. R, 1983, Theory of Fiscal Policy in An Islamic State, dalam J. Res. Islamic. Econ, Vol.1 No. 1.

Hafidhuddin, Didin, 2002, Zakat Dalam Perekonomian Modern, Jakarta: Gema Insani.

Hartoyo, Sri, 29 Juli 2010, Mengenal Pusat Zakat Umat Persis Garut dalam Iqtishodia, Jurnal Ekonomi Islam Republika.

Hasan, Riaz, 2006, Keragaman Iman, Studi Komparatif Masyarakat Muslim, Jakarta: PT. RajaGrafindo Persada.

Jahar, Asep Saefuddin, Agustus 2008, Zakat Antar Bangsa Muslim, Menimbang Posisi Realistis Pemerintah dan Organisasi Masyarakat Sipil dalam Zakat \& Empowering, Jurnal Pemikiran dan Gagasan, Vol. 1, No. 4.

Kahf, Monzer, 1997, Potential Effects Of Zakah On Government Budget, dalam IIUM Journal of Economics \& Management 5, No. 1.

Karim, Adiwarman, 2002, Ekonomi Islam Suatu Kajian Ekonomi Makro, Jakarta: The International Institute of Islamic Thought (IIIT Indonesia).

Mannan, M. Abdul, 1997, Teori dan Praktek Ekonomi Islam, Yogyakarta: PT. Dana Bhakti Prima Yasa.

Miftah, A. A., Pembaharuan Zakat Untuk Pengentasan Kemiskinan Di Indonesia, dalam Jurnal Innovatio, Vol. VII, No. 14, Juli-Desember 2008.

Mubariq, Ahmad, 2000, Zakat untuk Pengentasan Kemiskinan Beberapa Isu Kebijakan, dalam Eko Suprayitno, 2005, Ekonomi Islam Pendekatan Ekonomi Makro Islam dan Konvensional, Yogyakarta, Graha Ilmu.

Nasution, Mustafa Edwin, et al, 2006, Pengenalan Eksklusif Ekonomi Islam, Jakarta, Kencana. Norvadewi \& Akhmad Nur Zaroni, 2009, Pendayagunaan Zakat Produktif di Lembaga Zakat dan Pengarubnya terhadap Peningkatan Usaha Ekonomi Umat (Studi Komparatif di BAZ Propinsi Kaltim 
dan LAZ DPU Kaltim), Hasil Penelitian, Samarinda, P3M Stain Samarinda.

Qardawi, Yusuf, 1997, Norma dan Etika Ekonomi Islam, Jakarta, Gema Insani Press. , 2007, Hukum Zakat, Jakarta, Litera AntarNusa.

Razak, Nasruddin, 1973, Dienul Islam, Bandung, PT. Al Ma'arif.

Shihab, M. Quraish, 1994, Membumikan Al Qur'an, Fungsi dan Peran Wabyu Dalam Kebidupan Masyarakat, Bandung, Mizan.

Saidi, Zaim, dkk, 2006, Kedermawanan Untuk Keadilan Sosial, Jakarta: Piramedia

Sumadi, (Direktur LAZ DPU Kaltim), 2011, dalam Nurani, Mitra Peduli Untuk Berbagi. Majalah Bulanan LAZ DPU Kaltim (Media Informasi Donatur).

, Dari MUNAS FOZ Untuk Kesejabteraan Umat, dalam Majalah NURANI Edisi No. 24 Thn V/2012, LAZ DPU Kaltim

Susamto, Akhmad Akbar, 2003, Zakah As Deductible For Taxable Income: A Macroeconomic Perspektive, dalam IQTISAD Journal of Islamic Economics, Vol. 4, No. 2.

Susetyo, Heru, Agustus 2008, Peran Negara dalam Pengelolaan Zakat: Perspektif Negara Kesejahteraan dan Praktek Negara-negara Tetangga, dalam Zakat \& Empowering, Jurnal Pemikiran dan Gagasan, Vol. 1, No. 4.

Sairin, Sjafri, 2002, Perubahan Sosial Masyarakat Indonesia; Perspektif Antropologi, Jogjakarta: Pustaka Pelajar.

Soelaeman, Munandar, 1995, Ilmu Sosial Dasar.Jakarta: PT.Eresco

Taufiqullah, H.O, 2004, Zakat dan Pemberdayaan Ekonomi Umat, Bandung, BAZ Prov. Jabar.

The Pew Forum on Religion and Public Life, 2009, "Mapping the Global Muslim Population, A Report On The Size and Distribution of The World's Muslim Population”, viewed, Mei 2011.

Pirac, 2002, Investing in Our Selves ;Giving and Fund Raising In Indonesia. Phillipine: Asian Development Bank.

Zaman, S. M. Hasanuz, Januari 1993, Islamic Criteria For The Distribution Of Tax Burden (The Mix of Direct and Indirect Taxes and The Offsetting Fuction of Zakat), dalam Journal of Islamic Economics, Vol.3, No. 1. 